\title{
Lidil
}

Revue de linguistique et de didactique des langues

Acquisition et enseignement de la morphographie

\section{Morphological awareness and the Spelling of Homophone Forms in European Portuguese}

João Rosa

\section{CpenEdition}

\section{Journals}

Electronic version

URL: http://journals.openedition.org/lidil/873

DOI: $10.4000 /$ lidil. 873

ISSN: 1960-6052

\section{Publisher}

UGA Éditions/Université Grenoble Alpes

\section{Printed version}

Date of publication: 1 December 2004

Number of pages: 133-146

ISBN: 2-914176-11-2

ISSN: $1146-6480$

\section{Electronic reference}

João Rosa, « Morphological awareness and the Spelling of Homophone Forms in European

Portuguese », Lidil [Online], 30 | 2004, Online since 29 January 2008, connection on 05 May 2019.

URL : http://journals.openedition.org/lidil/873 ; DOI : 10.4000/lidil.873 


\title{
MORPHOLOGICAL AWARENESS AND THE SPELLING OF HOMOPHONE FORMS In European Portuguese
}

\author{
João RoSA *
}

The aim of this study is to describe the acquisition of the discrimination in the spelling of two homophone but not homograph forms (<-ice $>/<$-isse $>$ ) and consider whether morphological awareness predicts this discrimination.

The above forms are pronounced in the colloquial pattern as [is] but their spelling differs according to the grammatical function of the word. The first, <-ice $>$, is a derivational suffix that makes abstract nouns ('maluquice', foolishness). The second, $<$-isse $>$, is a sequence of two constituents (the thematic vowel $<-i>$ and the morpheme of tense/mode/aspect $<-s s e>$ ) occurring in the first and third persons singular of the subjunctive of verbs whose infinitive form ends in <-ir> ('fugir'/ 'se eu fugisse', meaning, run away/if I ran away).

Because two different spellings exist for the same sound and none of the spellings can be predicted from phonology, it is expected that children show marked difficulties in mastering this discrimination.

Bryant et al. (2000) and Nunes et al. (1997 a, b) showed that English children work out the problems of homophony in the endings of regular and irregular verbs in the past (for example 'kissed' and 'lost' end in the same [t] sound) by concentrating first on a phonological basis. After a phonological

* João Rosa, Escola Superior de Educação de Lisboa, Portugal.

$<$ jmsrosa@hotmail.com> 
stage children develop a progressive differentiation towards morphological strategies. This differentiation starts with unsystematic assignment of phonological and morphological spelling patterns, goes through periods of generalisation of a morphological pattern (<-ed >) to non-verbs and irregular verbs, before getting to a differentiation of the only context where the morpheme <-ed > can be used, i.e., regular verbs. They showed that developing morphological spelling strategies is a long process, not achieved before 10 to 11 years of age.

Aidinis (1998) also found evidence of a first phonological phase, in the development of morphological spellings by Greek children.

Evidence for the use of a phonological strategy, at the initial stages of spelling, was also established by Fayol et al. (1999). They examined the development of spelling of silent morphemes that mark the number in nouns, adjectives and verbs in the French language and found that children tended, on a first phase, to omit the spelling of what is silent, although they showed some awareness of those markers on comprehension tasks. On a second phase, children showed improved awareness in understanding the meaning of the presence or absence of plural markers in the comprehension task, but continued to find difficult to use those markers in the spelling task. Only after several years did children achieve a progressive automation in the spelling.

Brissaud and Sandon (1999) studied children's acquisition of correct spelling of verb morphemes that are homophone in French. For example, in "expliquer, expliquait, expliqué, expliquée..." all the inflexional end morphemes <-er $>$, $<$-ait $>$, <-é $>$, <-ée $>$ sound as/E/. They found consistent improvement throughout schooling and identified different spelling strategies used to overcome homophony. Younger children (7- to 8-years old) concentrated on spellings that were in accordance with verb endings. They usually tended to select the morpheme for the infinitive <-er >, as a "pivot" marker of the grammatical class, verbs. Children continued to experience difficulties, until they were 15 -years-old, although progress in spelling performance improved linearly. Older children also showed simplification strategies making recur- 
rent errors which were hypothesised as «economic responses towards rules that are difficult to master» (p. 55).

Morphological awareness plays a specific role in the development of spelling, as shown in some studies that examined the relation between morphological awareness and consistency in the spelling of morphologically related stems (Smith, 1987; Carlisle, 1988; Fowler et Liberman, 1995; Nunes, 1998 ; Aidinis, 1998). Few studies examined whether there is a relation between morphological awareness and discrimination in the spelling of homophone forms (Da Mota, 1995 ; Aidinis, 1998; Nunes et al., 1997 a, b). No research examined this issue in the European Variant of Portuguese.

The study that is reported here uses a longitudinal design to evaluate the development of discrimination in the spelling of $<$-ice $>/<-$ isse $>$ homophone forms and whether there is a predictive relation between morphological awareness and spelling discrimination.

Two hypotheses are tested.

1. There is an increase with grade in the ability to use discrimination in the spelling of $<$-ice $>/<$-isse $>$ homophone forms.

2. There is a predictive relation between morphological awareness and discrimination of $<$-ice $>\mid<-$ isse $>$, which cannot be explained by individual differences in level of instruction or general intelligence.

\section{Participants}

There were 184 children in the study, from 2 state-supported primary schools, in the greater Lisbon area, in Portugal. Participants were randomly selected from the school register by the experimenter. The average number of children in each classroom was around 25 but no more than 10 children from each classroom were included.

All children had European Portuguese as their first language and no diagnosed sensory or cognitive impairments. The sample covered a wide range of socio-economic backgrounds. 
When the first session (A) of the data collection took place, children were at the end of the last term in Grades 1, 2 and 3. In Session B, six months later, they were at the beginning of grades 2, 3 and 4, respectively. In Session C, again six months later, they were at the end of grades 2,3 and 4, respectively.

The mean ages (and standard deviations) in Session A were 83.31 (3.71), 95.72 (3.18), 107.31 (3.64) months for Grades $1(\mathrm{~N}=64), 2(\mathrm{~N}=61)$ and $3(\mathrm{~N}=59)$, respectively.

\section{Design}

Children were assessed three times (Sessions A, B and C) on their awareness of morphology, and on discrimination in the spelling of $<$-ice $>/<$-isse $>$ forms.

Awareness of morphology was assessed with three measures. The Word Analogy and Sentence Analogy tasks were repeated in the three sessions; the Pseudo-word Interpretation Task was introduced in sessions B and repeated in Session C.

Discrimination in the spelling of $<-$ ice $>/<$-isse $>$ forms was assessed with a spelling task in the three sessions. It contained words and pseudo-words. Pseudo-words were intended to provide control for lexical knowledge.

In this design the outcome measures are Discrimination in the Spelling of Words (or Pseudo-words), and the predictors are the three morphological awareness measures, Word Analogy, Sentence Analogy and the Pseudo-word Interpretation Task. Grade and IQ were entered as covariates or control factors.

\section{Materials and procedure}

\section{The morphological awareness measures}

Children were seen individually and assessed with the three tasks of morphological awareness, Word Analogy, Sentence Analogy and the Pseudo-word Interpretation. Because no measures were available in European Portuguese, these tasks 
were adapted from measures created by Nunes et al. (1997 a, b ; Nunes, 1998), and used in studies with English children. These measures assess children's explicit awareness of morphological relations, either whether they are aware of analogies between words of the same grammatical categories or whether they access, recognise and interpret the constituent morphemes (stems and affixes) of linguistic stimuli.

According to the instructions in Nunes et al. (1997 a), the experimenter used two finger puppets to present the first two tasks. In the Word Analogy task, the first puppet 'said' a word (e.g. 'andar', to walk) and the second 'repeated'the word with a change in its derivational or inflectional components (e.g. 'andou', he walked). Then the first puppet 'said' a third word (e.g. 'tremer', to shake) and the child was required to take the place of the second puppet and produce the fourth word ('tremeu', he shook). The procedure was the same with the Sentence Analogy task, where the puppets 'said'sentences instead of single words.

Example of the Word Analogy Task:

Director (director)/dirigiu (directed) - Escritor

(writer)/Escreveu (wrote)

Example of the Sentence Analogy Task:

O menino brinca muito (The boy plays a lot)/Os meninos

brincam miuto (The boys play a lot) - O menino corre muito (The boy runs a lot)/Os meninos correm muito (The boys run a lot).

The accurate answers that children were expected to give are in bold.

One practice trial (PT) with feedback was provided before the experimental trials. No feedback was given thereafter.

Each item was scored as correct (1) when the child made the correct morphological transformation by analogy. A score of $(0)$ was given otherwise.

The Pseudo-word Interpretation task measures children's ability to access, recognise, and interpret morphemes. Each stimulus is formed by morphemes that exist in the language, a stem and an affix, in a combination that does not form a word. This configuration controls for direct lexical access to the 
meaning of the stimulus. For example, in the pseudo-word 'inalegre', formed by a prefix < in- > plus the stem < alegre $>(u n+$ joyful $)$, the child has to provide an interpretation showing that the meaning of each morpheme was accessed.

The children were given four derived words as practice items, first. The aim of introducing examples was to explain that words have different morphemes that can be recognised and that influence word meaning.

There were 20 experimental items, half presented without sentence context, the remaining within sentence context.

Examples (accurate answers are given in bold):

"Tesourador»: someone who works with scissors

Para construir uma casa preciso de um «pedrador»: someone who works with stone

Children's answers were scored as correct (1) when an explanation that included the meanings of both the stem and the affix was provided. A score of (0) was given if only one morpheme was correctly recognised or an unrelated answer was given.

The three morphological awareness measures were presented to each child individually in a quiet room. The tasks were presented and performed orally, and the experimenter wrote down children's answers.

\section{The spelling task}

The spelling task was performed in Sessions A, B and C. There were 32 items assessing discrimination in the spelling of $<$-ice $>/<$-isse $>$ forms. There were 8 words and 8 pseudo-words assessing the spelling of the <-ice $>$ and 8 words and 8 pseudo-words for $<$-isse $>$. Pseudo-words were intented to provide control for lexical knowledge. The test items were interspersed in a list of 96 stimuli. These were orally presented by the experimenter, in a sentence context. If sentence context was not provided it would be impossible to determine the grammatical status of the pseudo-words and therefore, no spelling choice was possible.

The whole spelling task took place in a different room and in small groups of 6 to 10 children. 
The procedure consisted of reading the target word first, then the whole sentence and finally repeating the target word to spell, as in the following examples:

"Parvoice». "Tu disseste uma grande parvoíce"

"Parvoice"

"Fugisse ». «Não me apanhavas se eu fugisse».

«Fugisse»

No feedback was given throughout the task.

\section{The standardised measure}

In Session A, each child was seen individually in a quiet room and presented with a shortened version of WISC standardised for the Portuguese population by Marques (1970).

\section{Results}

\section{Analyses of spelling discrimination}

The spellings were scored as correct (1) for morphological spellings, or incorrect $(0)$ if otherwise. After calculating the number correct and incorrect, each child's score was transformed into a discrimination score corrected for chance, using Guilford's formula, $S=R-(W / n-1)$ (Guilford, 1954). In this formula, $S$ is the discrimination score, $R$ is the number of right answers, $W$ is the number of wrong answers and $n$ is the number of spelling possibilities. This score weighs what the child knows by what he or she does not know yet, considers the effect of number of spelling choices (the higher the number the greater the difficulty) and controls for spelling choices that are, statistically, explained by chance.

Five spelling possibilities, used most frequently by children, were considered as phonologically acceptable, independently of possible violation of contextual rules. These were $<$-ice $>,<$-isse $>,<$-ise $>,<$-içe $>$ and $<-$ i-se $>$. After applying this formula, a distribution of scores with a middle value of 0 (zero) meaning that the amount correct equals the amount incorrect is obtained. Because there are 8 correct spellings for each phonetic form [is], the extreme positive possible value is +16 (both forms systematically discriminated) and the 
extreme negative possible value is - 16 (no discrimination because both forms are systematically wrong).

Analyses of reliability showed that the spelling task measured the same issue, over time, consistently. Alphas of .92, .84 and .80 for Words and of $.85, .82$ and .74 for Pseudowords, in Sessions A, B, and C, respectively, are a clear indication of good internal consistency.

Analyses of skewness, showed that normality of distributions could be assumed either in words or pseudo-words.

The next analysis examined whether children improved their spelling across sessions and grade and whether the mean differences were significant.

Table 1 displays the means and standard deviations for discrimination of the homophone forms $<$-ice $>/<-$ isse $>$.

\begin{tabular}{|c|c|c|c|c|c|c|c|c|c|}
\hline & \multicolumn{3}{|c|}{ Session A } & \multicolumn{3}{|c|}{ Session B } & \multicolumn{3}{|c|}{ Session C } \\
\hline & \multicolumn{3}{|c|}{ Last Term of Grades } & \multicolumn{3}{|c|}{ First Term of Grades } & \multicolumn{3}{|c|}{ Last Term of Grades } \\
\hline & 1 & 2 & 3 & 2 & $\mathbf{3}$ & 4 & 2 & 3 & 4 \\
\hline$N=$ & 64 & 61 & 59 & 64 & 61 & 59 & 64 & 61 & 59 \\
\hline$<-i c e>1<$-isse $>$ & -1.05 & 125 & 236 & -.76 & & 4.31 & 1.96 & 301 & \\
\hline Words & (3.87) & $(4,44)$ & $(4.20)$ & (4.22) & $(4.78)$ & $(4.24)$ & (4.71) & (4.81) & $(4.51)$ \\
\hline$\langle-i c e\rangle \mid<-$ isse $\rangle$ & -1.09 & 1.90 & 2.57 & -1.03 & 1.90 & 3.29 & 1.64 & 2.25 & 2.87 \\
\hline Pseudo-words & (4.16) & $(4,64)$ & $(3.99)$ & (3.93) & $(4.59)$ & (3.78) & (4.53) & (3.98) & $(4.2)$ \\
\hline
\end{tabular}

Table I - Means and Standard Deviations (in brackets) for spelling discrimination of homophone forms <-ice $>\mid<$-isse $>$, in words and pseudo-words, by Session and Grade.

The table shows that children at the end of grade 1 in Session A, and beginning of grade 2 in Session B, discriminate the forms negatively, and only reach positive ground in the last term of grade 2 in Session C. This pattern is observed both in the spelling of words and pseudo-words. Children in the middle grades show a positive discrimination in all sessions and progress across sessions when spelling words. Positive discrimination is also found in the spelling of pseudowords but progress is only apparent from Sessions B to C. Children in the higher grades show a higher level of discrimi- 
nation in both words and pseudo-words, with more apparent progress between Sessions A and B than between Sessions B and $C$.

In order to examine whether these mean differences were significant, a mixed analysis of variance was conducted with discrimination of $<$-ice $>/<-$-isse $>$ words in Sessions A, B and $C$ as a repeated-measures within subjects factor, and Grade as a between-subjects factor.

This analysis revealed that there were significant effects of Session and Grade. Pairwise comparisons (Least Significance Differences -LSD) showed that the scores increased significantly from Session A to Session B and from Session B to Session C. Post-hoc tests (Student Newman-Keuls -SNK) also showed that discrimination increased significantly with Grade.

A second mixed analysis of variance was conducted with discrimination of $<$-ice $>/<$-isse $>$ pseudo-words. Significant effects of Session and Grade were also found. Pairwise comparisons (LSD) revealed that discrimination scores in Session A did not differ from the scores in Session B. There were significant differences when discrimination from Sessions B to $\mathrm{C}$ and from $\mathrm{A}$ to $\mathrm{C}$ were compared. Post-hoc tests (SNK) revealed that discrimination increased significantly with Grade.

It can be concluded that children improved significantly their discrimination of $<$-ice $>/<$-isse $>$ words and pseudowords throughout the study. This supports the hypothesis that discrimination improves with Grade.

\section{Analyses of a predictive relation between morphological awareness and spelling discrimination}

In order to examine the second hypothesis, fixed order hierarchical multiple regressions were conducted. These assess the specific contribution $\left(\mathrm{r}^{2}\right.$ change) of earlier measures of morphological awareness in predicting later performance in spelling discrimination, i.e., whether one can hypothesise that there is a likely causal relation between the two.

In all regressions, Grade and IQ were entered as the first two steps to rule out that any relations between morphological 
awareness and spelling discrimination could be explained by shared variance with those two major control factors.

In each regression, one of the morphological awareness measures was entered as the third step.

It was found that after stringent controls for shared variance explained by Grade and IQ, significant unique contributions of morphological awareness were still found over periods of 6 and 12 months: Sentence Analogy in Session A significantly predicted discrimination in Session $\mathrm{B}$ in the spelling pseudo-words $\left(\mathrm{r}^{2}\right.$ change $\left.=.020, \mathrm{p}<.05\right)$; Sentence Analogy in Session B significantly predicted discrimination in Session $C$, in words $\left(r^{2}\right.$ change $\left.=.044, p=.002\right)$ and pseudo-words $\left(\mathrm{r}^{2}\right.$ change $\left.=.026, \mathrm{p}<.05\right)$. The Pseudo-word Interpretation in Session B significantly predicted discrimination in Session $C$, in words $\left(r^{2}\right.$ change $\left.=.050, p=.001\right)$ and pseudo-words $\left(r^{2}\right.$ change $\left.=.079, p<.001\right)$. Finally, Sentence Analogy in Session A predicted the level of discrimination of words, twelve months later, in Session $C\left(r^{2}\right.$ change $=.022, p$ $<.05$ ) but no significant prediction appeared in the spelling of pseudo-words.

\section{Discussion and conclusions}

This study demonstrated that 6- to 9-year-old children progress in their ability to use spelling discrimination, and that this progress is strongly dependent on children's awareness of morphological relations. This indicates that what children know about grammatical transformations and their ability to access, identify, and interpret the meaning of stems and affixes, has a specific effect on their ability to spell homophone forms morphologically. Such effect cannot be explained by the concurrent contribution of Grade and IQ. This demonstration in another alphabetic language - Portuguese - adds support for findings in other languages such as English (Bryant et al, 1997; Carlisle, 1988; Nunes et al., 1997 a, b ; Rubin, 1988) and Greek (Aidinis, 1998) for a possible causal role of morphological awareness in the development of morphological spelling strategies. It must be acknowledged that the evidence provided in this study is indicative of some of the initial and intermediary complexi- 
ties of the process of constructing morphological discrimination of homophone forms. More evidence is needed on the achievement of a complete morphological strategy that allows for systematic discrimination in the spelling of these forms. More evidence is also needed that the spelling of pseudowords is informed by morphology. This is the ultimate test that a morphological rationale, not based on lexical knowledge, is attained. In order to achieve that, one needs to analyse how older children, and adults, develop this discrimination, and whether or when systematic assignment is reached.

It is suggested in the literature (Nunes et al., $1997 \mathrm{a}, \mathrm{b}$; Bryant et al., 2000; Fayol et al., 1999) that children start to work out the problems of morpheme homophony by concentrating first on a phonological spelling strategy.

The spelling discrimination of the sound [s] in <-ice $>/$ $<$-isse $>$ raises the question of whether Portuguese children may start with a phonological approach. In fact, the most likely phonological representation for the sound/s/in the two forms would be $\langle s\rangle$. To begin with, $\langle s\rangle$ is not contextually acceptable in any of the forms, as $<s>$ between oral vowels would represent [z]. Other representations for this sound [s] are $\langle$ ç $\rangle,\langle\mathrm{c}\rangle$ or $\langle$ ss $\rangle$. The spelling with $\langle$ ç $\rangle$ is not contextually acceptable as well because it can not occur before $<\mathrm{e}\rangle$. The representations by $\langle\mathrm{c}\rangle$ and $<\mathrm{ss}\rangle$ are both justifiable by contextual rules: $\langle\mathrm{c}\rangle$ can be used before $\langle\mathrm{e}\rangle$ and $<$ ss $>$ can be used between oral vowels. However, these contextual rules apply in any of the two forms, therefore adding to ambiguity.

Thus, there is not a clear phonological matrix that secures a significant proportion of the spelling options of these forms, in Portuguese. As a consequence, children have to manage spelling information based on an entangled puzzle of contextual rules, taken as productive, but that only account for some contexts.

This suggests that in terms of a theory of the development of morphology in the spelling, it might be necessary to separate situations where children can work out spelling strategies anchored on a phonological matrix from those where a high level of unpredictability has to be dealt with from the very start. 
There are two main educational consequences from this study. First, children develop their spelling discrimination throughout schooling but further improvement will result from capitalising on the development of explicit understanding of morphological relations. Second, a systematic effort must be done by researchers and teachers, in order to map those spelling situations where predictable rules apply and those that are unpredictable. It has been shown recently (Rosa, 2003) that teachers are not explicitly aware of which grammatical distinctions ( $<$-ice $>=$ abstract nouns / $<-$ isse $>=$ verbs in the subjunctive) make the spelling of these forms fully predictable. Improvements on teacher training and on the designing of instruction materials are certainly needed. Both developmental and intervention studies are also required examining the acquisition of morphological spelling strategies and whether the teaching of morphological rules makes a difference in spelling discrimination. Bryant et al. (1997), Fayol et al. (1999) and Nunes et al. (2003) found positive effects of morphological interventions in the spelling. The use of intervention studies to confirm causal relations is a needed development, relatively unexplored so far.

\section{References}

Aidinis, A. (1998): Phonemes, Morphemes and Literacy Development: Evidence From Greek, Unpublished Ph.D. Thesis, Department of Child Development and Learning, University of London, Institute of Education.

Brissaud, C., Sandon, J-M. (1999): L'acquisition des formes verbales en $/ E /$ à l'école élémentaire et au collège, entre phonographie et morphographie, Langue Française: L'orthographe et ses scripteurs, 124, 40-57.

Bryant, P., Devine, M., Ledward, A., Nunes, T. (1997): Spelling with apostrophes and understanding possession,

British Journal of Educational Psychology, 67, 91-110.

Bryant, P., Nunes, T., Snaith, R. (2000) : Children learn an untaught rule of spelling, Nature, 403, 13 January.

Carlisle, J. F. (1988): Knowledge of derivational morphology 
and spelling ability in fourth, sixth, and eighth graders, Applied Psycholinguistics, 9, 247-266.

Da Mota, M. (1995): The Role of Grammatical Knowledge in Spelling, Unpublished D. Phil. Thesis, University of Oxford, Oxford, U.K.

Fayol, M., Thevenin, M.-G., Jarrousse, J.-P., Totereau, C. (1999): From Learning to Teaching to Learning French Written Morphology, In $T$. Nunes (Ed.), Learning to Read: an Integrated View from Research and Practice, Kluwer Academic Publishers.

Fowler, A.E., Liberman, I. Y. (1995): The role of phonology and orthography in morphological awareness, In L.B. Feldman (Ed.), Morphological Aspects of Language Processing, 157-188, Hillsdale, NJ : Erlbaum.

Guilford, J. P. (1954): Psychometric methods, McGraw-Hill Book Company, Inc., New York, $2^{\text {nd }}$ Edition.

Marques, F. (1970): Manual da escala de inteligência para crianças (WISC): Adaptação $e$ aferição para Portugal, Instituto de Alta Cultura- Centro de Estudos de Psicologia e de História da Filosofia, Lisboa.

Nunes, T. (1998): Developing children's minds through literacy and numeracy, University of London, Institute of Education.

Nunes, T., Bryant, P., Bindman, M. (1997a): Morphological spelling strategies: developmental stages and processes, Developmental Psychology, 33, 4, 637 - 649.

Nunes, T., Bryant, P., Bindman, M. (1997b): Learning to spell regular and irregular verbs, Reading and Writing: An Interdisciplinary Journal, 9, 5-6, 427-449.

Nunes, T., Bryant, P. et Olsonn, J. (2003): Learning morphological and phonological spelling rules: an intervention study, Scientific Studies of Reading, 7, 3, 289-308.

Rosa, J. (2003): Morphological awareness and spelling development, Unpublished Ph.D. Thesis, Department of Psychology, Oxford Brookes University, Oxford, U.K.

Rubin, H. (1988): Morphological knowledge and early writing ability, Language and Speech, Vol 31, 4, 337-355.

Smith, M. L. (1987): Spelling and Morpheme Recognition: A methodological study, Unpublished Masters Thesis, University of Alberta, Edmonton. 


\section{Acknowledgement}

I would like to thank Terezinha Nunes for her support on the design and methodology of this study as well as for her feedback and help on the the analysis and interpretation of the data.

Address for correspondence: João Rosa, Escola Superior de Educação de Lisboa, Campus de Benfica do IPL, 1549-033, Lisboa, Portugal.

Phone +351214396601 ; e-mail <jmsrosa@ hotmail.com> 